\title{
The Mechanism of the Impact of Team Climate and Team Psychological Safety on Team Innovation Performance
}

\author{
Yun-Mei Li ${ }^{1, a,{ }^{*}}$, Yan Cao ${ }^{2, b}$, Da-Wei Li ${ }^{3}$ \\ ${ }^{1}$ Center for industrial policy and management research, Wuhan University of Science and \\ Technology, 123-116-2, Gangdu Garden, Qingshan District, Wuhan, China \\ ${ }^{2}$ Center for industrial policy and management research, Wuhan University of Science and \\ Technology, No.947, Heping Avenue, Qingshan District, Wuhan, China \\ alymwust@163.com, bcaoyanchn@163.com \\ *Corresponding author
}

Keywords: Team climate, Team psychological safety, Team innovation performance, Mediation effects.

\begin{abstract}
Project teams are widely used in enterprises to foster remarkable innovation performance. However, the overall effect of project team is often difficult to achieve in the practical application of China's enterprises. Based on literature review, the mechanism of how team climate and team psychological safety contribute to team innovation performance was set up and examined in this study. Data were collected from 45 high-tech innovation teams of China and analyzed statistically using Structural Equation Modelling (SEM) approach. Results indicated that (1) team climate and team psychological safety positively influences team innovation performance, that (2) team psychological safety, partially and fully, mediates the effects of team climate on team innovation performance, and that (3) the mediation effects of team psychological safety are mainly shown through three components of team climate, which are co-worker trust, co-worker support and supervisor support.
\end{abstract}

\section{Introduction}

Innovation occupies a crucial role in enhancing enterprise core competence, and project teams are generally used as a new method to facilitate and foster remarkable innovation performance. It is a subject worthy of deep exploration and research as how to make project teams function well, and many scholars have done research into this subject. It is proved that team climate is a key factor in promoting team innovation performance $[1,2] .$. That is, team climate directly influences individual creativity, whereas it has an indirect effect on team creativity. However, the prior research simply analyze the relationship between these two factors, and the mechanism of how team climate contributes to team innovation performance is not paid much attention to, which is the object of this study. Based on interpersonal relationships theory, a focus on the interactions among supervisors and subordinates and among co-workers is emphasized, and team psychological safety is introduced as a mediator to explore the relationship between team climate and team innovation performance. This study is of great value to underscore the subjectivity of team members to ameliorate team climate, and enhance the psychological safety and innovation performance.

\section{Variables and Hypotheses}

\section{Team Innovation Performance}

Team innovation performance is considered to be difficult to be measured due to the facts that innovation inputs are hard to measure, innovation process is highly uncertain and innovation outputs are hysteretic in time. Barrick and Stewart (1998) suggest that subjective estimation should be adopted to measure this construct[3]; Lovelance et al (2001) develops a questionnaire in the angle of innovation outputs, , measuring the degree of product innovation, number of ideas, and the ability to adapt to changes[4]; Grayr (2001) points that team innovation ability enhancement and team innovation action improvement can result in an increase of team innovation performance, 
since that strong innovation ability and positive innovation action are the basis of innovation performance[5]. In accordance with Grayr, this study considers team innovation ability and team innovation action as components of team innovation performance.

\section{Team Climate}

Team climate is the shared perception of the team members towards work environment which impels them trust each other, cooperate with each other and achieve the team object together (Anderson and West) [6]. It is found to be a recessive team culture essentially and can improve employee satisfaction and stimulate spirit of devotion. In the view of interpersonal relationship, this study divides team climate into three dimensions of team trust, team identity and team supporting, each dimension measured in two levels of supervisor-subordinate and coworker-coworker.

\section{Team Psychological Safety}

According to Edmondson, psychological safety refers to a shared belief that the team is safe for interpersonal risk taking [7]. High psychological safety means that team members are willing to express their inner ideas, contribute their own intelligence, respect and support other members' viewpoints and they are prepared to undertake the responsibility of their commitment. Introduced as a mediator in this study, team psychological safety is extracted as 7 aspects of understanding, tolerance, acceptance, support, mutual-help, affirmation and fosterage to examine the relationship between team climate and team innovation performance.

\section{Relationship between Team Climate and Team Innovation Performance}

Good team climate creates a relaxed and open atmosphere for team members to share knowledge and exploit potential. Li finds that team members shape strong team recognition and contribute to team innovation when they are treated fairly and supported positively [8]. Zhong proposes that trust of team members as well as the same vision has a positive influence on team innovation [9]. Hence, we pose the following hypotheses:

Hypothesis 1: (a) supervisor trust, (b) supervisor support, (c) supervisor recognition, (d) co-worker trust, (e) co-worker support, (f) co-worker recognition being as the components of team climate have positive impact on team innovation performance.

\section{Relationship between Team Climate and Team Psychological Safety}

As a new form of organization management, project team develops its unique climate related to working nature, working environment, characteristics and etc.. The climate in turn affects team members' feelings and actions imperceptibly. In a team with comfortable climate, team members show high psychological safety and tend to express themselves and help others. With this in mind, we propose hypothesis as follows:

Hypothesis 2: (a) supervisor trust, (b) supervisor support, (c) supervisor recognition, (d) co-worker trust, (e) co-worker support, (f) co-worker recognition being as the components of team climate have positive impact on team psychological safety.

\section{Relationship between Team Psychological Safety and Team Innovation Performance}

Scholars generally agree on the claim that psychological safety is supposed to be an essential factor to assess the team innovation. It is more likely to spark afflatus and thus generate innovation achievement in a low-pressure team (Song) [10]. This leads to the following hypothesis:

Hypothesis 3: team psychological safety produces a positive effect on team innovation performance.

\section{The Mediating Role of Team Psychological Safety}

Team climate affects psychological feelings of team members to a great extent, with the psychological feelings reflected in their actions. In this way, team innovation performance is promoted gradually. Based on the foregoing discussion, hypothesis 4 is proposed as follows.

Hypothesis 4: team psychological safety serves as a mediator between team climate and team 
innovation performance.

The above hypotheses are summarized in Fig.1. This hypothesized structural model will be empirically analyzed in Section Three.

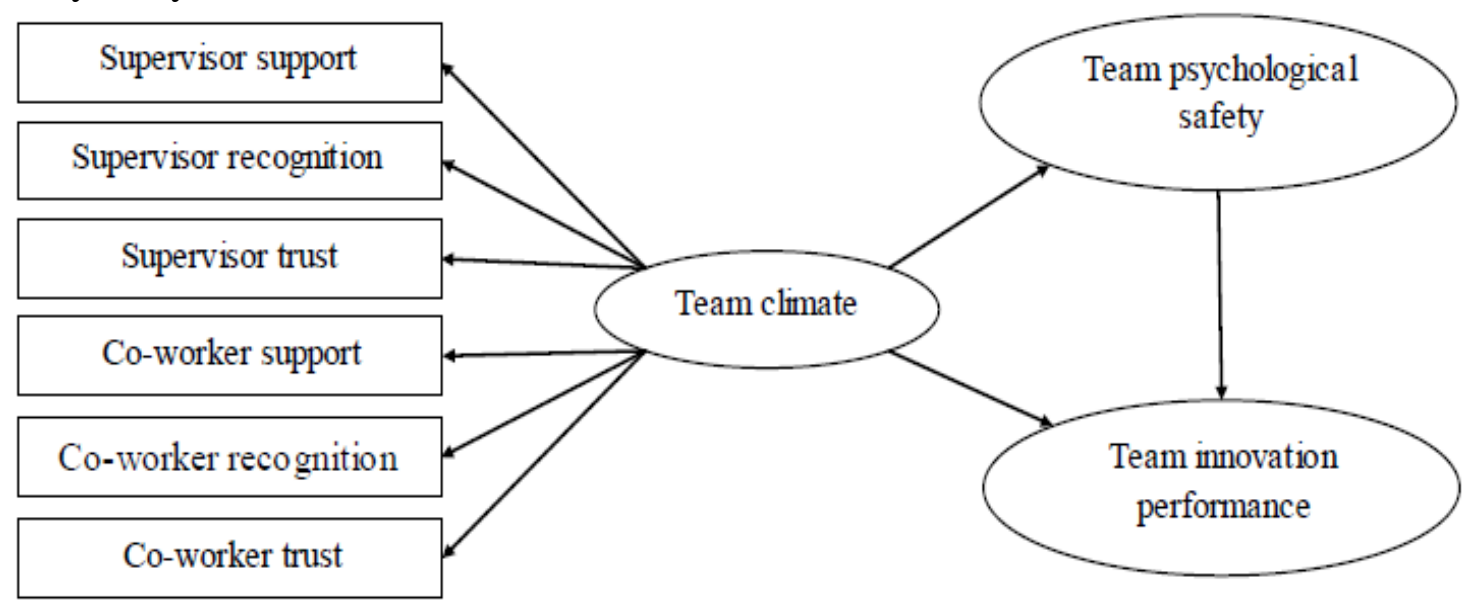

Fig. 1 the Hypothesized Model

\section{Methodology}

\section{Sampling frame and size}

The sample for this study consists of 50 innovation teams, comprising 300 employees from 60 high-tech enterprises and R\&D organizations in Wuhan, China. Eliminating 5 teams for the initial questionnaires that have missing data, we get an effective sample of 45 teams, and total usable responses are 274. Respondents consist of 84 females (30.7\%) and 190 males (69.3\%); majority of teams $(89.9 \%)$ are made up of more than 4 team members. The educational background ranges from junior college degree to doctor degree.

\section{Measurement of constructs}

The model divides the examined variables into five basic components-team trust, team support, team recognition, team psychological safety and team innovation performance. Appropriate measurement items for the five constructs were identified in the available literature and modified based on preliminary interviews, in a 5 -point Likert-type scale $(1=$ strongly disagree, $5=$ strongly agree). We evaluate team trust with a tram trust scale developed by Rauniar, team support with a team support scale developed by Eisenberger, and team recognition with the scale developed by Colquitt. And these three constructs are measured among the supervisor and subordinates and among co-workers. Psychological safety is measured with seven items adopted from a psychological safety scale developed by Edmondson (1999). A sample item from the scale is, "If you make a mistake at work, it is often held against you" (reverse coded). Innovation performance is measured in two dimensions of innovation ability and innovation actions, with 6 items adopted from Grayr's scale.

\section{Results}

\section{Preliminary analysis}

Data were analyzed with AMOS 17.0 based on structural equation modelling (SEM) principles. To ensure the construct validity, the confirmatory factor analysis was conducted on the scales (see Table 1). All the scores of KMO (>0.8) and Bartlett testing meet the criteria of convergent validity. On the other hand, reliability was assessed by means of Cronbach's alpha $(\alpha)$. Given that all $\alpha$ scores were above 0.7 (see Table 2), the design of questionnaire content in this study has a good credibility as well as the data this study collected. 
Tab.1 KMO and Bartlett testing

\begin{tabular}{|c|c|c|c|c|}
\hline & $\begin{array}{c}\text { Team climate among } \\
\text { supervisor and subordinates }\end{array}$ & $\begin{array}{c}\text { Team climate among } \\
\text { co-workers. }\end{array}$ & $\begin{array}{c}\text { Team psychological } \\
\text { safety }\end{array}$ & $\begin{array}{c}\text { Team innovation } \\
\text { performance }\end{array}$ \\
\hline KMO & .911 & .904 & .819 & .857 \\
\hline Bartlett & $1.416 \mathrm{E} 3$ & 745.783 & 36.000 & 302.164 \\
\hline Sig. & .000 & .000 & .000 & .000 \\
\hline
\end{tabular}

Tab.2 Cronbach's alpha testing

\begin{tabular}{|c|c|}
\hline Scale & Cronbach's $\alpha$ \\
\hline Team climate among supervisor and subordinates & 0.940 \\
\hline Team climate among co-workers. & 0.938 \\
\hline Team psychological safety & 0.841 \\
\hline Team innovation performance & 0.849 \\
\hline total & 0.957 \\
\hline
\end{tabular}

\section{Path Analysis and Hypotheses Testing}

The model testing. Since preliminary statistics demonstrated adequate data integrity, the relationship testing between team climate, team psychological safety and team innovation performance was conducted. AMOS 17.0 was used to test the hypotheses. The $\chi 2 / \mathrm{df}$ value $(=1.38)$ smaller than 3 and RMSEA value $(=0.033)$ smaller than 0.05 as well as other fit indexes indicated a high degree of goodness-of fit (RMR=0.026, GFI=0.969, IFI=0.914, CFI=0.902).

The standardized path coefficients of team climate to team innovation performance and team psychological safety are 0.20 and 0.85 respectively; both $\mathrm{P}$ value is 0.000 , namely the effects are significant, supporting hypotheses 1 and 2. Team psychological safety is positively related to the level of team innovation performance, and the relationship is significant ( $\mathrm{p}=0.034)$, supporting H3. We can conclude that team climate influences team innovation performance directly and indirectly through team psychological safety. The mediator role of team psychological safety is verified

Tab.3 SEM Path Verification Summary

\begin{tabular}{|c|c|c|c|c|c|}
\hline Hypothesis & Independent variables & Dependent variables & $\begin{array}{c}\text { Standardized } \\
\text { path coefficient }\end{array}$ & P value & Support \\
\hline H1 & Team climate & Team psychological safety & $* * *$ & $* * *$ & Yes \\
\hline H2 & Team climate & $\begin{array}{c}\text { Team innovation } \\
\text { performance }\end{array}$ & $* * *$ & Yes \\
\hline H3 & $\begin{array}{c}\text { Team psychological } \\
\text { safety }\end{array}$ & $\begin{array}{c}\text { Team innovation } \\
\text { performance }\end{array}$ & $* * *$ & $* * *$ \\
\hline \multicolumn{5}{|c|}{ Indexes of goodness-of-fit } \\
\hline \multicolumn{7}{|c|}{$\chi^{2} / \mathrm{df}=1.38 ; \mathrm{RMR}=0.026 ; \mathrm{GFI}=0.969 ; \mathrm{IFI}=0.914 ; \mathrm{CFI}=0.902 ; \mathrm{RMSEA}=0.033$} \\
\hline
\end{tabular}

The sub-model testing. In order to examine the inner mechanism how team climate affects team psychological safety and team innovation performance, we proposed to identify team climate as team trust, team support and team recognition. The results showed no-significant t-values on paths between trust and support of supervisor as antecedents and the other constructs as endogenous variables, with other hypotheses approved. Hence the conceptual model was re-specified with the aim of achieving a more parsimonious model (see Fig. 2).

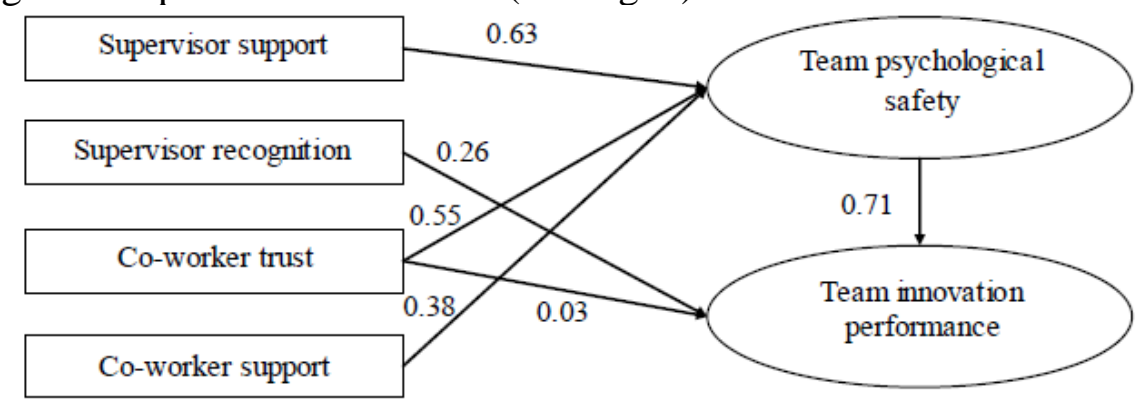

Fig. 2 Modified mediating model 
A good fit of the model to the data was established based on only slight modifications. $\chi 2 / \mathrm{df}$ $=1.75, \mathrm{RMR}=0.023, \mathrm{RMSEA}=0.017$, GFI $=0.908$ and $\mathrm{CFI}=0.975$, all reaching the satisfactory level. The standardized effects were presented in Table 4.

Tab.4 Results of hypotheses testing

\begin{tabular}{|c|c|c|c|c|c|c|}
\hline \multirow{2}{*}{ Hypothesis } & \multirow{2}{*}{$\begin{array}{c}\text { Independent } \\
\text { variables }\end{array}$} & \multirow{2}{*}{ Dependent variables } & \multicolumn{3}{|c|}{ Standardized effects } & \multirow{2}{*}{ Support } \\
\hline & & & Direct & Indirect & Total & \\
\hline H1a & Supervisor trust & Team innovation performance & - & 0.45 & 0.45 & Yes \\
\hline $\mathrm{H} 1 \mathrm{~b}$ & $\begin{array}{l}\text { Supervisor } \\
\text { support }\end{array}$ & Team innovation performance & 0.26 & - & 0.26 & Yes \\
\hline $\mathrm{H} 1 \mathrm{c}$ & $\begin{array}{l}\text { Supervisor } \\
\text { recognition }\end{array}$ & Team innovation performance & - & - & - & No \\
\hline H1d & Co-worker trust & Team innovation performance & - & - & - & No \\
\hline H1e & $\begin{array}{l}\text { Co-worker } \\
\text { support }\end{array}$ & Team innovation performance & 0.03 & 0.39 & 0.42 & Yes \\
\hline H1f & $\begin{array}{l}\text { Co-worker } \\
\text { recognition }\end{array}$ & Team innovation performance & 0.63 & - & 0.63 & Yes \\
\hline $\mathrm{H} 2 \mathrm{a}$ & Supervisor trust & Team psychological safety & 0.63 & - & 0.63 & Yes \\
\hline $\mathrm{H} 2 \mathrm{~b}$ & $\begin{array}{l}\text { Supervisor } \\
\text { support }\end{array}$ & Team psychological safety & - & - & - & No \\
\hline $\mathrm{H} 2 \mathrm{c}$ & $\begin{array}{l}\text { Supervisor } \\
\text { recognition }\end{array}$ & Team psychological safety & - & - & - & No \\
\hline $\mathrm{H} 2 \mathrm{~d}$ & Co-worker trust & Team psychological safety & - & - & - & No \\
\hline $\mathrm{H} 2 \mathrm{e}$ & $\begin{array}{l}\text { Co-worker } \\
\text { support }\end{array}$ & Team psychological safety & 0.55 & - & 0.55 & Yes \\
\hline $\mathrm{H} 2 \mathrm{f}$ & $\begin{array}{l}\text { Co-worker } \\
\text { recognition }\end{array}$ & Team psychological safety & 0.38 & - & 0.38 & Yes \\
\hline
\end{tabular}

The results showed that four component variables of team climate, namely supervisor support, supervisor recognition, co-worker trust and co-worker support, influence team innovation performance directly or indirectly, supporting $\mathrm{H} 1 \mathrm{a}, \mathrm{H} 1 \mathrm{~b}, \mathrm{H} 1 \mathrm{e}$ and $\mathrm{H} 1 \mathrm{f}$. In details, team psychological safety serves a complete mediator between supervisor support and team innovation performance, and services a partial mediator between co-worker trust and team innovation performance and between co-worker support and team innovation performance. Additionally, supervisor recognition influences team innovation performance directly. The total standardized effects is ranked in the order of supervisor support (0.45), co-worker trust (0.42), co-worker support (0.27) and supervisor recognition (0.26). On the other hand, seen in the paths between the mentioned four components of team climate and team psychological safety, supervisor support, co-worker trust and co-worker support significantly and directly impact team psychological safety, supporting $\mathrm{H} 2 \mathrm{a}, \mathrm{H} 2 \mathrm{e}$ and $\mathrm{H} 2 \mathrm{f}$.

\section{Discussion}

(1) Team climate influences the extent of team innovation performance directly and indirectly through the mediation of team psychological safety, seen from the model. The standardized path coefficient of team climate to team innovation performance is 0.20 , suggesting a direct positive impact between team climate and team innovation performance; the mediation effect of team psychological safety is then verified between the relationships. Therefore, the supervisor should provide adequate guidance and show sincere care for the ordinates to build a relaxed and open team climate, thus ensuring favorable psychological safety of every team member and promoting innovation performance.

(2) Supervisor support provides most effect towards innovation performance and makes the most of team psychological safety, making itself the key factor to improve team innovation performance, seen from the sub-model. It can be concluded that team supervisor plays a vital role in the process. Additionally, supervisor support, co-worker trust and co-worker influence team psychological safety positively. A communication system is suggested to promote friendship of team members and to develop trust and support. In this way, team psychological safety is ensured and team innovation 
performance is further advanced.

\section{Acknowledgement}

This research was financially supported by the Research Project of Humanities and Social Sciences in the Education Department of Hubei Province (14D008) and Graduate Student Teaching Research Project in Wuhan University of Science and Technology (Yjg201424).

\section{References}

[1] P G Bain, L Mann, M A Pirola, The innovation imperative: the relationship between team climate, innovation, and performance in research and development teams, J. Small Group Research. 32(2001) 55-73.

[2] F B Zhong, C Peng, Y Chen, The impact of team climate to individual creativity and team creativity, J. Value Engineering. 15(2011) 12-13.

[3] M R Barrick, G I Stewart, et al, Relating member ability and personality to work-team process and team effectiveness, J. Journal of Applied Psychology.,83(1998) 377-391.

[4] K Lovelance, P L Shapiro, Maximizing cross-functional new product teams' innovativeness and constraint adherence: a conflict communications perspective, J. Academy of Management Journal. 44(2001) 779-793.

[5] R J Grayr, Organizational climate and project success, J. International Journal of Project Management. 19(2001) 103-109.

[6] M A West, N R Anderson. Innovation in top management teams, J. Journal of Applied Psychology. 6(1996) 680-693.

[7] A C. Edmondson, Psychological safety and learning behavior in work teams, J. Administrative Science Quarterly. 44(1999) 350-383.

[8] S X Li, Q Z Liang, Y Meng, A study on the relationship between team diversity climate, cohesion and creativity, J. Soft Science. 26(2012) 91-95.

[9] F B Zhong, Research on relationship among team's internal social capital, team climate and team creativity, D. Nanjing University of Aeronautics and Astronantics. 2011.

[10] Kai Song, the impact of team trust and team climate on innovative action among first-line employees, D. University of International Business and Economics. 2010. 